\title{
CUES FOR THE SPORTS TRAINING OF PRESCHOOL AND PRIMARY SCHOOL CHILDREN
}

\author{
Silvia TEODORESCU ${ }^{1}$, Constanța URZEAL $\breve{A}^{1 *}$ \\ ${ }^{1}$ National University of Physical Education and Sport, Faculty of Physical Education and Sport, \\ Bucharest, Romania \\ *Corresponding author: ritmicuta@yahoo.com
}

https://doi.org/10.35189/dpeskj.2020.59.4.1

\begin{abstract}
In recent decades, specialists have observed a decrease in the age at which children start performance activity in most sports as a result of increasingly higher athletic performance worldwide. Moreover, the dynamic of growth and development processes has changed, and one can notice the early onset of the signs of puberty and adolescence. The purpose of this paper is to highlight some important benchmarks of sports training for preschoolers and young school children, as a theoretical support for coaches involved in performance sports activity. Coaches obviously want to prove that they have effective training strategies to force the preparation of children in different stages of growth and development when their biological potential prevents them from providing the expected response to a demand. A good coach will always consider the physical, cognitive, emotional and social development of the child, being directly responsible for their long-term modelling. The training of preschool and young school children follows different strategies compared to advanced athletes, starting from the premise that a child is not a miniature adult. Thus, coaches should look beyond the need to achieve the best possible result in the shortest time and establish long-term training objectives for children. Such an approach will be possible only by knowing in detail the growth and development characteristics specific to each age stage, as well as children's motor skills, predominantly playful manifestations and their desire to prove to others that they can. In conclusion, successful training for preschool and young school children is based on the interaction between play - train-compete - repeat!
\end{abstract}

Keywords: sport, training, children.

\section{Introduction}

Predicting performance at young ages is difficult to achieve because not all functional abilities can be identified early and not all directions in which performance capacity will progress can be anticipated, given that motor development does not always have the same pace as physical development.

Even if obtaining good results in competitions is a priority for any coach, there is no guarantee that young athletes in beginner groups will remain in performance activity. A number of children will only benefit from appropriate sports practice for an active lifestyle, without achieving remarkable results in competitions. The benefits of engaging as many children as possible in sports activities is materialised, on the one hand, by increased chances to detect individuals who are talented for performance and, on the other hand, by ensuring participants a high quality of life. The study by Moeijes et al. (2018) demonstrates that practising a sport during childhood is positively associated with the child's psychosocial health.

Depending on the sport, children start training at preschool or young school age, but there are also branches of sport where the selection takes place much later. In recent decades, specialists have observed a decrease in the age at which children start performance activity in 
most sports as a result of increasingly higher athletic performance worldwide. Moreover, the dynamic of growth and development processes has changed, and one can notice the early onset of the signs of puberty and adolescence. This dynamic, which is contained in secular trends along with children's predilection for sedentary lifestyles and reduced time spent outdoors and which is also influenced by macro-environmental and demographic changes (Dollman et al., 2005), is directly reflected in performance sport.

In these conditions, the most efficient pace for the process of modelling children towards high performance is difficult to establish, given the dynamic of their normal physiological development. Coaches obviously want to prove that they have effective training strategies to force the preparation of children in different stages of growth and development when their biological potential prevents them from providing the expected response to a demand. The application of training stimuli will be done taking into account that the growth and development pace is different from one child to another (Rogol, 2003). A good coach will always consider the physical, cognitive, emotional and social development of the child, being directly responsible for their long-term modelling.

The purpose of this paper is to highlight some important benchmarks of sports training for preschoolers and young school children, as a theoretical support for coaches involved in performance sports activity.

\section{Topic Addressed}

\section{Characteristics of preschool children}

Somatically, the weight and height of preschool children should be within normal limits, although the somatic parameter is not relevant at this age. During this stage, children increase their body weight by about $2 \mathrm{~kg}$ per year and their height by $4-5 \mathrm{~cm}$. At the age of $4-5$ years, girls weigh between $12.9 \mathrm{~kg}$ and $20 \mathrm{~kg}$, and boys between $13.1 \mathrm{~kg}$ and $19.9 \mathrm{~kg}$. The height of girls ranges between $94 \mathrm{~cm}$ and $108 \mathrm{~cm}$, and that of boys between $95 \mathrm{~cm}$ and $110 \mathrm{~cm}$. (World Health Organisation, 2017)

From a functional point of view, the exercise capacity of preschool children is reduced, which is why their practice should be interspersed with breaks. Due to their psychological characteristics, namely the fact that they get bored quickly and do not have the patience to practise, it is not possible to use a large number of repetitions for the same exercise.

In cognitive terms, Piaget states that the preschooler's thinking is preoperational, unsystematised, and egocentric, with a tendency to see things only from their own perspective. Language is in full development, and communication skills are influenced by several factors: family, social environment and educational environment (de Jesus Alvarenga Carvalho et al., 2016).

As regards motor development, it is based on gross motor skills and the development of movement control, balance, coordination of agonist and antagonist muscles, coordination of upper and lower limbs. The motor development of the preschool child is considered as a critical component of the educational intervention due to the beneficial effects of motor exploration on other developmental areas (Battaglia et al., 2019). 
Preschoolers can be enrolled in beginner groups for performance sport, without having the certainty that they will remain in activity for a long time and will confirm their value through subsequent results. Even if children begin a systematised and regular training process, the motor education achieved at this age does not mean that they will complete all stages of sports training and will become champions. In sports where beginner groups are made up of preschool children, the first training stage should focus on their need for movement and curiosity, gradually replacing basic motor skills with specific ones. Therefore, the contents should aim to develop general motor skills and psychomotor skills so that the athlete can exploit them later when learning a sport-specific technique and developing fitness for life (Arnett et al., 2008). The individual learning pace will also be taken into account (Lee et al., 2014).

Preschoolers show an increased need for movement and play, with an obvious willingness to learn new things. They prefer playful activities during which they assume various roles, play characters and explore the surrounding world through their basic motor skills while being unaware of the danger of certain motor actions. Imitation is very effective in the process of forming motor skills and language skills (De Giacomo et al., 2018). The fastest learning occurs when the contents are taught using a metaphorical language adapted to their area of knowledge and when they are transposed into an imaginary world. The spontaneity, lack of inhibitions and energy that characterise preschoolers facilitate their initiation into a branch of sport, with the mention that they have difficulty respecting the rules and forming a sports discipline. Children easily engage in motor activities to "conquer" the surrounding environment and discover their "powers" or skills. It is very important for them to succeed in performing various motor skills by themselves and thus demonstrate to the adults in their lives that they are able to do certain movements. They gain confidence in their own capabilities when people around them are satisfied with their way of performing actions. Children of this age have a very strong desire to make others proud of them and are afraid of disappointing others.

Children gain the ability to compare with each other around the age of 6-7 years, appreciating as difficult the motor tasks that only a few children in the group can perform. Psychologists recommend not to inculcate too early the desire to win, but to cultivate the motivation of children to demonstrate what they know and to do sport with pleasure.

\section{Characteristics of young school children}

The young student's behaviour is strongly influenced by the beginning of school activity. Framed by specialists between the ages of $6 / 7$ and $10 / 11$ years, this stage is thought to be the happiest period in life. Even if the family tends to put the child's intellectual development at the forefront, engaging in a systematic sports activity is not incompatible with the school load and individual study (Spengler et al., 2019).

The morpho-functional growth and development of children in this prepubertal period are accelerated and uniform. In somatic terms, there are no differences between boys and girls. During growth, the child's hormone levels, muscles, bones, joints, energy system and cardiovascular system undergo changes. To these are added the psychosocial factors that will constantly influence the training process because children develop not only physically but 
also emotionally and intellectually. Their capacity for interpretation, analysis and reflection improves. When they reach school age, children pay more attention to people with whom they interact and begin to understand teamwork and relationships with other group members.

Systematic training has a positive impact on body weight, in the sense of decreasing adipose tissue and increasing the percentage of muscle tissue, and implicitly on energy metabolism.

At the cortical level, specialists notice an imbalance between the fundamental cortical processes, with a predominance of excitation processes to the detriment of inhibition ones. There is also an improvement in kinaesthetic, vestibular and visual analysers, with direct effects on performing motor tasks in sports training. If, during the previous age stage, the child was part of a group whose main activity was play, at school, the child is included into a group to which they want to belong (Ungar, 2010). Still preserved as an essential means in child education, play has a share that progressively decreases in all activities as puberty approaches. In sports training, the playful contents of the previous stage will be gradually replaced by specific motor tasks, without completely giving up the entertaining means. If the selection takes place during this school stage, play will continue to have an important share in order to attract the child to the sports activity concerned.

It is worth noting that children have the ability to subordinate the mechanism and cognitive role of thinking to their perceptions, which are better organised, systematised and influenced by observation. Psychologists point out that, through practice, perceptions become more effective at this age. They also highlight an increase in discriminative sensitivity and perceptual thresholds, which is directly reflected in both the acuity of analysers and technical acquisitions.

The stage between 6 and 10 years old is regarded as the golden age of learning. Therefore, for sports training too, it is a suitable period for learning the specific technique. The child needs to be constantly stimulated to learn new technical skills starting from the basic skills (Higgs et al., 2010), but without making a too fast transition from one movement to another, given that these acquisitions, depending on their degree of complexity, require different time periods for consolidation and stabilisation.

According to Durand (2011), the psychomotor repertoire of children engaged in performance activity at this age must include: reaction speed; spatiotemporal orientation; the ability to combine and organise different seemingly disparate sensory elements in a coherent form; perceptual speed or the ability to make a quick and error-free judgment on the similarities and differences between two movements; the ability to identify and locate a known perceptual configuration within a larger set that also has unknown elements; the ability to operate with mental pictures and anticipate the subsequent trajectory or position of an object; the ability to quickly select a response adapted to a visual stimulus; distributed attention; selective attention; capacity for anticipation; precision of motor control; manual dexterity in handling objects of different sizes; stability in maintaining some arm and hand positions for a longer period of time; intersegmental coordination; general coordination; general body balance.

Even if the progressive development of muscles allows performing strength exercises, external loads, static contractions and maximum-shape demands are not recommended. 
Studies demonstrate that there are no differences between girls and boys regarding strength development until the age of 10-11 years (Holm et al., 2008).

The objectives related to speed development can be achieved in sports training within the limits of knowing the optimal age for the improvement and genetic conditioning of this fitness component. Reaction speed can be particularly improved at this age, and the improvement of spatiotemporal coordination is positively reflected in the execution speed of the child.

General endurance to aerobic exercise is good at school age, this motor skill being successfully developed during the prepubertal stage provided that the physical effort is properly dosed. Statistics show that, in the case of continuous running, the young student resists for 7 minutes at 6-7 years old, and later, at the age of 10-11 years, boys resist 15 minutes, and girls, 12 minutes. It is recommended to develop endurance in children by integrating play in the set of means planned to lay the basis for the physical condition required by specialisation and to prevent injury (Zwolski et al., 2017). Moreover, endurance exercises increase self-confidence (Bergeron et al., 2015) and, in girls, they positively influence skeletal development (Sugimoto et al., 2015). It has been demonstrated that the development of endurance in children also has beneficial effects on their motor learning progress. Thus, running, jumping and throwing will be improved following endurance exercises performed with intensities between $60 \%$ and $80 \%$ (Behringer et al., 2011).

The components of coordination skills develop differently. Thus, spatiotemporal orientation is poor in children aged 6-7 years but improves towards the end of the stage. Precision is better in boys compared to girls and stagnates during primary school. Particular importance should be given to the development of coordination in young school children, knowing that all technical skills depend on the child's level of coordination (Sánchez-Lastra et al., 2019).

Mobility is facilitated by the growth and development processes that have not yet been completed. For this reason, children can practise to improve their range of motion in the spine, shoulder and coxofemoral joints, being recommended to use dynamic exercises and avoid hyperextension, where possible (Drabik, n.d.).

\section{Effort management in the training of children}

Sports training is considered an educational act that cannot be managed without respecting the growth and development characteristics of the child. Even if any educational approach has better chances of success if started early, effort management in children becomes a sensitive process, in the sense that training demands should not disrupt growth. Knowing that any instructive-educational process in which the laws of development are not taken into account may have negative effects on individual evolution, training strategies need to be well thought-out and constantly adapted to the body reactions to exercise.

Improper effort management at a young age predisposes the athlete to injury due to prolonged exposure of the body to specific exercise (Hall et al., 2015) performed with high volumes and intensities, in the absence of appropriate recovery. Moreover, excessive early specialisation can lead to overtraining and withdrawal of the athlete from activity (DiFiori et al., 2014). 
Some specialists believe that young children should try several sports for a multipurpose development of their performance capacity and later to specialise in a single sport. For those who choose a particular sport, the periods with intense demands and specific means need to be carefully monitored, isolated and oriented towards integrative neuromuscular training. These measures are necessary to prevent burnout, overuse and overtraining (Myer et al., 2016). Such an approach may seem inconceivable to certain coaches, especially those from Eastern Europe, who are predominantly followers of early specialisation (Malina, 2010). The option for this training strategy can be explained by the fact that coaches have to face the pressure of achieving performance as soon as possible, which is exerted by both superiors and children's parents.

Effort management in children involves a long-term prospective approach to the training process so that they can develop normally from a physiological point of view and can cope with subsequent specific demands. Athlete longevity depends on the proper effort management throughout all stages of training in relation to the biological and chronological development of the child and the performance goals. Performance at any price is cancelled over time when, after retiring from activity, former athletes complain about health problems (Schmitt et al., 2001). Therefore, early overuse prevents the body from coping with the specific demands of senior age, and the interruption or even withdrawal from activity becomes inevitable.

Consequently, one of the essential points in the training of children is to determine the parameters that allow the quantification of practice during a lesson or a microcycle but also during the preparation periods of a macrocycle. It is important to establish the ratio between general and specific training within the macrostructure, depending on the age and level of preparation of athletes, in the sense of increasing the share of general training for beginner groups and the share of specific training for advanced groups.

The means of training used by the coach should allow designing the construction, restructuring and recombination of learned motor skills that can be easily transferred to the area of technical elements and procedures or technical and tactical actions specific to the branch of sport. In terms of coordination skills, it is necessary to improve the ability of analysers to recognise as quickly as possible the optimal muscle tensions needed for a good adjustment of the degrees of freedom of movement and maintaining balance, spatial orientation and precision.

\section{Place and role of the competition in the training of children}

The main landmark in the training of athletes is competition, which becomes more and more important as athletes complete the training stages and make the transition from one category of sports classification to another. The participation of children in competitions is increasingly frequent as they grow older, in parallel with changing the objective pursued from getting used to the competition atmosphere to achieving a performance-based result.

Regardless of the sport, young school children engaged in performance activity will be trained to participate in competitions. Most sports federations organise official national competitions for children aged between 8 and 10 years. The specific content of the competition event will be approached in the technical and tactical training, but without 
completely giving up the general means. As to the management of emotions and motivation for competition, specialists recommend for young athletes to be taught to celebrate their own achievements in competitions and enjoy participation even if they are not winners. Accepting defeat at this age and keeping the motivation to continue sports activity become two important landmarks in the prospective training of children (Pandel, 2015). Specialists promote a training strategy based on limiting criticism and reducing the recall of the competitive result during training. They also propose rewarding efforts and interpreting competitive performance as a life lesson, as feedback for the training process.

It is known that children aged 8-9 years have an increased interest in rules and are vehemently opposed to cheating in all forms of playful interaction. This tendency can also be seen in motor activities, even if children are constantly seeking solutions that make their efforts more efficient. As children grow older, they gradually focus on the relationship between effort and result, trying to achieve success with minimal effort. We specify that young athletes, generally are not able to distinguish situations in which a superior result is based on talent or extra effort.

Some studies show that children should not be involved too early in competitive activities, while others highlight exceptional results achieved in various fields by individuals whose "taste" for competition has been exploited since an early age. Cultivating the passion for the chosen sports branch or event, the spirit of perseverance and sports discipline along with fair play and respect should be among the objectives of child participation in competitions (Hertting, 2010). Competitions should bring positive stimuli and provide children with the pleasure of competing with others, given that they are at an age when the emerging sense of self-worth is based on attributes such as optimism, independence, tolerance, ambition, ability to know others and transposition ability.

Childhood is the age when the sense of self-esteem appears, which includes success and the pursuit of goals. The child considers cooperation and confrontation as two versions of the same game. Competitions should highlight more the ability of each child and less the effect of competition, and all children should have equal opportunities for success.

Therefore, when planning competitions for children, coaches should take into account that:

- until around the age of 6 years, the child's need to compare with others is not obvious, especially since they do not have the ability to keep their attention focused for a long time;

- around the age of 7-8 years, the duration of focused attention increases and becomes more stable, which favours compliance with the competition rules; at this age, the child begins to feel the need to compete with others. As a result, the coach should plan competitions in which children: express their skills; participate with pleasure; regularly achieve some success; progress and thus educate their ability to manage a possible failure.

- between 8 and 10 years old, children can benefit from a so-called competition calendar, which includes different types of competitions meant to both ensure the assessment of their own level of training (self-assessment) and give them the opportunity to compare with other athletes. However, the achievement of training objectives should be a priority rather than reaching performance goals. 
- around the age of 12 years, the number of competitions begins to increase, so we can talk about a competition calendar that will decisively influence the training periodisation.

Specialists point out that excessive focus on competition in the training of children may even lead to giving up sports activity for reasons related to either early burnout of performance capacity due to disruption of growth processes and the occurrence of health problems or because of losing motivation for performance sport. The cognitive and emotional maturity that children must show when participating in competitions influences the manifestation of their performance capacity. Thus, the result achieved by a child should also be interpreted in terms of each one's growth and development characteristics, with less emphasis on the desire to win in the lower sports classification categories.

When the participation of children in competitions is influenced by parents (Baxter-Jones et al., 2003) or other social factors that expect them to achieve extraordinary results, competition becomes a stressor. When expectations are exaggerated, victory turns into defeat, which is hard for a child to bear. Children do not have the ability to assess themselves and cannot understand why they have not been winners too. Poor management of emotions triggered by the result achieved in a competition may even lead to giving up sports activity.

Neither sports training nor personal satisfaction makes children give up their sports career, but success standards that cannot be met by them.

The participation of children in competitions entails their complex involvement from a motor, physiological, cognitive, emotional, motivational and social point of view, using all their resources for performance in a more or less conscious way (depending on the age stage). The simultaneous action of stressors, which is specific to competitive situations, puts high demands on the child's body (Kostka et al., 2012), which is why appropriate means of recovery have to be applied. Moreover, young children are not recommended to participate in a large number of competitions per year. However, this aspect is different from one sport to another, depending on the competitive system in force.

\section{Conclusion}

The training of preschool and young school children follows different strategies compared to advanced athletes, starting from the premise that a child is not a miniature adult. Thus, coaches should look beyond the need to achieve the best possible result in the shortest time and establish long-term training objectives for children. Such an approach will be possible only by knowing in detail the growth and development characteristics specific to each age stage, as well as children's motor skills, predominantly playful manifestations and their desire to prove to others that they can.

Summarising, successful training for preschool and young school children is based on the interaction between play - train - compete - repeat! (Figure 1). 


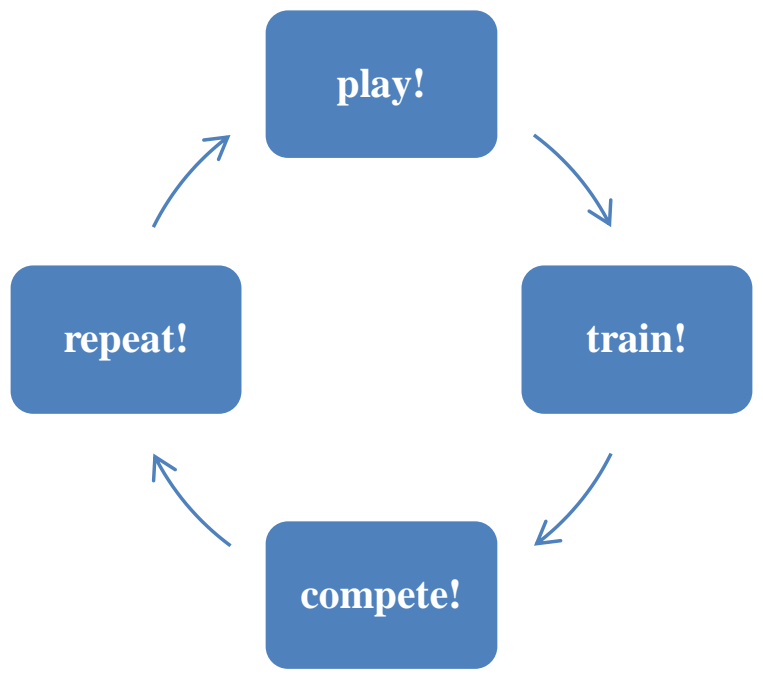

Figure 1. The interplay between the main cues for the sports training of children

\section{Acknowledgement}

This paper is made and published under the aegis of the National University of Physical Education and Sport in Bucharest, as a partner of program co-funded by the European Social Fund within the Operational Sectorial Program for Human Resources Development 20072013 through the project Pluri- and interdisciplinarity in doctoral and post-doctoral programs Project Code: POSDRU/159/1.5/S/141086, its main beneficiary being the Research Institute for Quality of Life, Romanian Academy.

\section{References}

Arnett, L. M., Van Beurden, E., Morgan, P. J.. Brooks, L. O.. \& Beard, J. R. (2008). Does childhood motor skill proficiency predict adolescent fitness? Medicine \& Science in Sports \& Exercise, 40(12), 2137-2144. https://doi.org/10.1249/mss.0b013e31818160d3

Battaglia, G., Alesi, M., Tabacchi, G., Palma, A., \& Bellafiore, M. (2019). The development of motor and pre-literacy skills by a physical education program in preschool children: A non-randomized pilot trial. Frontiers in Psychology, 9: 2694. https://doi.org/10.3389/fpsyg.2018.02694

Baxter-Jones, A. D. G., Maffulli, N., \& TOYA Study Group. (2003). Parental influence on sport participation in elite young athletes. Journal of Sports Medicine and Physical Fitness, 43(2), 250-255. https://europepmc.org/article/med/12853909

Behringer, M., Vom Heede, A., Matthews, M., \& Mester, J. (2011). Effects of strength training on motor performance skills in children and adolescents: A meta-analysis. Pediatric Exercise Science, 23(2), 186-206. https://doi.org/10.1123/pes.23.2.186

Bergeron, M. F., Mountjoy, M., Armstrong, N., Chia, M., Côté, J., Emery, C. A., Faigenbaum, A., Hall Jr, G., Kriemler, S., Léglise, M., Malina, R. M., Pensgaard, A. M., Sanchez, A., Soligard, T., Sundgot-Borgen, J., van Mechelen, W., Weissensteiner, J. R., \& Lars Engebretsen, L. (2015). International Olympic Committee consensus statement on youth athletic development. British Journal of Sports Medicine, 49(13), 843-851. https://doi.org/10.1136/bjsports-2015-094962 
de Jesus Alvarenga Carvalho, A., Aguiar Lemos, S. M., \& Horta de Figueirado Goulart, L. M. (2016). Language development and its relation to social behavior and family and school environments: A systematic review. CoDAS, 28(4), 470-479. https://doi.org/10.1590/2317-1782/20162015193

De Giacomo, A., Coppola, A., Tricarico, T., Terrenzio, V., Margari, M., Petruzzelli, M. G., \& Craig, F. (2018). Socioeconomic status and imitation on language acquisition in a sample of preschool children. Rivista di Psichiatria, 53(4), 199-204. https://doi.org/10.1708/2954.29696

DiFiori, J. P., Benjamin, H. J., Brenner, J. S., Gregory, A., Jayanthi, N., Landry, G. L., \& Luke, A. (2014). Overuse injuries and burnout in youth sports: A position statement from the American Medical Society for Sports Medicine. British Journal of Sports Medicine, 48(4), 287-288. http://dx.doi.org/10.1136/bjsports-2013-093299

Dollman, J., Norton, K., \& Norton, L. (2005). Evidence for secular trends in children's physical activity behaviour. British Journal of Sports Medicine, 39(12), 892-897. https://doi.org/10.1136/bjsm.2004.016675

Drabik, J. (n.d.). Theory and practice of coaching 2. Children \& sports training. http://www.hurdlecentral.com/Docs/Coaching/Drabik_Theory\&PracticeOfCoachingChildr enTraining.pdf

Durand, M. (2011). L'enfant et le sport [The child and sport]. Paris: PUF.

Hall, R., Barber Foss, K., Hewett, T. E., \& Myer, G. D. (2015). Sport specialization's association with an increased risk of developing anterior knee pain in adolescent female athletes. Journal of Sport Rehabilitation, 24(1), 31-35. https://doi.org/10.1123/jsr.2013-0101

Hertting, K. (2010). Leading with pedagogical tact - A challenge in children's sports in Sweden. Sport Science Review, 1-2, 127-147. https://doi.org/10.2478/v10237-011-0008-9

Higgs, C., Balyi, I., Way, R., Cardinal, C., Norris, S., \& Bluechardt, M. (2010). Developing physical literacy: A guide for parents of children ages 0 to 12. http://sportforlife.ca/wp-content/uploads/2016/12/DPL_ENG_Feb29.indd_.pdf

Holm, I., Fredriksen, P., Fosdahl, M., \& Vøllestad, N. (2008). A normative sample of isotonic and isokinetic muscle strength measurements in children 7 to 12 years of age. Acta Paediatrica, 97(5), 602-607. https://doi.org/10.1111/j.1651-2227.2008.00709.x

Kostka, T., Furgal, W., Gawroński, W., Bugajski, A., Czamara, A., Klukowski, K., Krysztofiak, H., Lewicki, R., Szyguła, Z., Tomaszewski, W., Trzaskam T., Widuchowski, J., Ziemba, A., \& Jegier, A. (2012). Recommendations of the Polish Society of Sports Medicine on age criteria while qualifying children and youth for participation in various sports. British Journal of Sports Medicine, 46(3): 159. http://dx.doi.org/10.1136/bjsports-2011-090043

Lee, M. C. Y., Chow, J. Y., Komar, J., Tan, C. W., \& Button, C. (2014). Nonlinear pedagogy: An effective approach to cater for individual differences in learning a sports skill. PLoS One, 9(8): e104744. https://doi.org/10.1371/journal.pone.0104744

Malina, R. M. (2010). Early sport specialization: Roots, effectiveness, risks. Current Sports Medicine Reports, 9(6), 364-371. https://doi.org/10.1249/jsr.0b013e3181fe3166

Moeijes, J., van Busschbach, J. T., Bosscher, R. J., \& Twisk, J. W. R. (2018). Sports participation and psychosocial health: A longitudinal observational study in children. BMC Public Health, 18(1): 702. https://doi.org/10.1186/s12889-018-5624-1

Myer, G. D., Jayanthi, N., DiFiori, J. P., Faigenbaum, A. D., Kiefer, A. W., Logerstedt, D., \& Micheli, L. J. (2016). Sports specialization, Part II: Alternative solutions to early sport specialization in youth athletes. Sports Health, 8(1), 65-73.

https://doi.org/10.1177/1941738115614811 
Pandel, H. (2015). Healthy competition is good for children. Institute of Public Affairs Review, 67(1), 30-33. https://ipa.org.au/ipa-review-articles/healthy-competition-is-good-for-children

Rogol, A. D. (2003). Growth, body composition and hormonal axes in children and adolescents. Journal of Endocrinological Investigation, 26(9), 855-860. https://doi.org/10.1007/bf03345236

Sánchez-Lastra, M. A., Varela, S., Cancela, J. M., \& Ayán, C. (2019). Improving children's coordination with proprioceptive training. Apunts. Educació Física i Esports, 136, 22-35. https://doi.org/10.5672/apunts.2014-0983.es.(2019/2).136.02

Schmitt, H., Brocai, D. R., \& Carstens, C. (2001). Long-term review of the lumbar spine in javelin throwers. The Journal of Bone and Joint Surgery, 83-B(3), 324-327. https://doi.org/10.1302/0301-620x.83b3.11386

Spengler, S., Kuritz, A., Rabel, M., \& Mess, F. (2019). Are primary school children attending full-day school still engaged in sports clubs? PLoS One, 14(11): e0225220. https://doi.org/10.1371/journal.pone.0225220

Sugimoto, D., Myer, G. D., Barber Foss, K. D., \& Hewett, T. E. (2015). Specific exercise effects of preventive neuromuscular training intervention on anterior cruciate ligament injury risk reduction in young females: Meta-analysis and subgroup analysis. British Journal of Sports Medicine, 49(5), 282-289. https://doi.org/10.1136/bjsports-2014-093461

Ungar, M. (2010). Why kids like to go to school, and why they don't. Psychology Today. https://www.psychologytoday.com/us/blog/nurturing-resilience/201004/why-kids-goschool-and-why-they-dont

World Health Organisation. (2017). World health statistics: Monitoring health for the SDGs. https://apps.who.int/iris/bitstream/handle/10665/255336/9789241565486eng.pdf? sequence $=1 \&$ isAllowed $=\mathrm{y}$

Zwolski, C., Quatman-Yates, C., \& Paterno, M. V. (2017). Resistance training in youth: Laying the foundation for injury prevention and physical literacy. Sports Health, 9(5), 436-443. https://doi.org/10.1177/1941738117704153 